\title{
Comportamento ingestivo e respostas fisiológicas de cabritos alimentados com dietas contendo torta de girassol oriunda da produção de biodiesel
}

\author{
[Ingestive behavior and physiological responses of goats fed with diets containing sunflower \\ cake from biodiesel production] \\ M.S.F.A. Agy ${ }^{1}$, R.L. Oliveira ${ }^{2}$, G.G.P. Carvalho ${ }^{2}$, A.G. Leão $o^{2}$, O.L. Ribeiro ${ }^{2}$, \\ A.R. Bagaldo ${ }^{3}$, R.D.X. Ribeiro ${ }^{4}$, M.D. Ribeiro ${ }^{5}$ \\ ${ }^{1}$ Instituto de Investigação Agrária de Moçambique - IIAM \\ ${ }^{2}$ Escola de Medicina Veterinária e Zootecnia - UFBA - Salvador, BA \\ ${ }^{3}$ Centro de Ciências Agrárias, Ambientais e Biológicas - UFRB \\ ${ }^{4}$ Centro de Ciências Agrárias - UFPB \\ ${ }^{5}$ Faculdade de Agronomia - Medicina Veterinária e Zootecnia - UFMT
}

\begin{abstract}
RESUMO
Avaliou-se o efeito de dieta com torta de girassol, oriunda da produção de biodiesel, sobre o comportamento ingestivo e a resposta fisiológica de 32 cabritos $1 / 2$ sangue Boer, não castrados, com peso médio inicial de $15,3 \pm 3,2 \mathrm{~kg}$ e idade média de 135 dias. Utilizou-se delineamento inteiramente ao acaso, com quatro tratamentos 0; $8 ; 16$ e 24\% de inclusão da torta de girassol e oito repetições. O tempo despendido com ruminação, ócio e mastigação total não foi influenciado pela dieta, e observou-se efeito linear crescente sobre o tempo de ingestão em min/período e em min/dia. A eficiência de ingestão e ruminação da matéria seca e da fibra em detergente neutro também não diferiu entre dietas. Quanto às respostas fisiológicas, as frequências respiratória e cardíaca e as temperaturas retal e superficial não sofreram influência da dieta. Concluiu-se que a torta de girassol pode ser incluída até $24 \%$ da matéria seca em dietas de cabritos $1 / 2$ sangue Boer sem comprometer o comportamento ingestivo e os parâmetros fisiológicos desses animais. $\mathrm{O}$ fornecimento de dietas com até $24 \%$ de matéria seca de torta de girassol não interfere no estresse calórico de cabritos.
\end{abstract}

Palavras-chave: caprino, ingestão, ruminação, temperatura retal, torta de oleaginosa

\begin{abstract}
The effect of diets with sunflower cake originated from biodiesel production on the ingestive behavior and physiological responses of 32 crossbred Boer goats, noncastrated, with initial weight of $15.3 \pm 3.2 \mathrm{~kg}$ and mean age of 135 days was evaluated. A completely randomized design with four treatments $(0,8,16$ and $24 \%$ of sunflower cake inclusion) and eight replicates was used. The rumination and idling times and the total chewing time were not affected by diets, but the ingestion time ( $\mathrm{min} /$ period and min/day) had an increasing linear effect. The rumination and ingestion efficiencies of dry matter and neutral detergent fiber also did not differ among diets. Regarding the physiological responses of animals, the heart and respiratory frequencies and the surface and rectal temperatures were not influenced by diets. Sunflower cake can be included up to 24\% DM in diets of crossbred Boer goats without compromising the ingestive behavior and physiological parameter of these animals. Under the climatic conditions evaluated the supply of diets with up to 24\% DM of sunflower cake does not mitigate or enhance the heat stress in kids.
\end{abstract}

Keywords: goat, intake, oleaginous cake, rectal temperature, rumination

\section{INTRODUÇÃO}

A caprinocultura de corte no Nordeste brasileiro vem passando por um processo de desenvolvimento expressivo, decorrente da importância econômica e social que esta atividade tem representado à população local, haja vista a geração de emprego e renda (Sousa, 2007) e, principalmente, pelo fato de a carne caprina ser um alimento altamente nutritivo. E embora esta região seja a maior detentora do rebanho caprino do país, muitos produtores têm

Recebido em 18 de abril de 2011

Aceito em 19 de julho de 2012

* Autor para correspondência (corresponding author)

E-mail: agleao@yahoo.com.br 
dificuldades em fornecer com regularidade, ao potencial mercado existente, carne de qualidade, em virtude, sobretudo, do custo elevado dos ingredientes proteicos e/ou energéticos comumente utilizados na dieta dos animais, que os tornam dependentes das pastagens naturais, resultando em baixa produtividade (Holanda Júnior, 2006).

Pesquisas realizadas com o intuito de proporcionar aumento da produção animal e redução dos custos com alimentação têm avaliado a utilização de alguns coprodutos da agroindústria, vastamente produzidos no país, como alternativa de alimentos para ruminantes (Borja et al., 2010; Correia et al., 2011; Macome et al., 2011; Agy et al., 2012; Palmieri et al., 2012). Segundo Oliveira et al. (2010), as tortas de oleaginosas oriundas da produção de biodiesel apresentam potencial de uso na alimentação de ruminantes, haja vista as consideráveis concentrações de proteína e extrato etéreo, que as caracterizam como alimentos proteicos e/ou energéticos, capazes de suprir boa parte das exigências nutricionais de proteína e energia dos animais.

O uso bem-sucedido dos coprodutos muitas vezes é limitado em razão do escasso conhecimento sobre as características nutricionais destes, bem como sobre o desempenho dos animais alimentados com esse tipo de ingrediente na dieta (Meneghetti e Domingues, 2008). O estudo do comportamento ingestivo dos caprinos é premente, pois, por meio deste, pode-se fazer a avaliação de alimentos e dietas (Dado e Allen, 1995) e, com isso, ajustar o manejo alimentar dos animais, buscando a obtenção de melhor desempenho (Mendonça et al., 2004).

É importante salientar que o comportamento ingestivo pode ser influenciado por fatores relacionados ao ambiente, ao animal e ao alimento (Campbell et al., 1992). Os animais modificam as atividades de ingestão de alimentos e água de acordo com a incidência dos elementos climáticos sobre eles (Souza et al., 2010), e, segundo Souza et al. (2007), em ambientes com temperaturas elevadas, nas quais a produção de calor excede a dissipação pelos animais, todas as fontes que geram calor endógeno são inibidas, principalmente o consumo dos alimentos e os metabolismos basal e energético, enquanto a temperatura corporal, a frequência respiratória e a taxa de sudação aumentam. Dessa forma, o conhecimento das variáveis climáticas, sua interação com os animais e as respostas comportamentais, fisiológicas e produtivas destes são preponderantes na adequação do sistema de produção, uma vez que as diferentes respostas dos animais às peculiaridades de cada região são determinantes no sucesso da atividade produtiva (Neiva et al., 2004; Souza et al., 2011).

O objetivo deste trabalho foi avaliar, sob a condição climática do Recôncavo Baiano, o comportamento ingestivo e a resposta fisiológica de cabritos $1 / 2$ sangue Boer alimentados com dietas contendo torta de girassol oriunda da produção de biodiesel.

\section{MATERIAL E MÉTODOS}

O experimento foi realizado entre outubro e dezembro de 2008, em aprisco localizado a $13^{\circ} 00^{\prime} 14^{\prime \prime}$ de latitude Sul e 38 30'34' de longitude Oeste, em zona litorânea. O clima da região, segundo a classificação de Köeppen, é o tropical úmido (Af), caracterizado pela elevada temperatura média anual $\left(25,3^{\circ} \mathrm{C}\right)$, precipitação média mensal superior a $60 \mathrm{~mm}$ e umidade relativa média do ar de $81 \%$ (Instituto..., 1992).

Foram utilizados 32 cabritos $1 / 2$ sangue Boer, machos não castrados, com peso corporal médio inicial de $15,3 \pm 3,2 \mathrm{~kg}$ e idade média de 135 dias. Os animais foram identificados, pesados, everminados e vacinados contra clostridiose. Em seguida, foram confinados em baias individuais de $1,0 \mathrm{~m}^{2}$, com piso ripado suspenso, equipadas com comedouros e bebedouros e dispostas em área coberta.

Os cabritos foram distribuídos em quatro tratamentos, constituídos por dietas com $0,8,16$ e $24 \%$ de inclusão da torta de girassol. As dietas foram calculadas de acordo com as exigências preconizadas pelo NRC (Nutrient..., 2007), para atender às exigências nutricionais de animais com $15 \mathrm{~kg}$ de peso corporal, para ganho de peso estimado em $100 \mathrm{~g} /$ dia. Os concentrados foram compostos pelos farelos de milho e soja, torta de girassol e sal mineral, e foi utilizado feno de Tifton-85 moído como volumoso, na relação volumoso:concentrado de 50:50, constituindo dietas isonitrogenadas (Tab. 1). 
Tabela 1. Proporção dos ingredientes das dietas experimentais (\%MS) de caprinos, de acordo com a inclusão de torta de girassol

\begin{tabular}{lcccc}
\hline \multirow{2}{*}{ Ingrediente } & \multicolumn{4}{c}{ Torta de girassol (\%) } \\
\cline { 2 - 4 } & 0 & 8 & 16 & 24 \\
\hline Farelo de milho & 32,91 & 30,17 & 27,41 & 24,69 \\
Farelo de soja & 15,40 & 10,22 & 5,08 & 0,00 \\
Torta de girassol & 0,00 & 7,94 & 15,84 & 23,65 \\
Premix vitamínico mineral $^{1}$ & 1,68 & 1,68 & 1,67 & 1,66 \\
Feno de Tifton-85 & 50,00 & 50,00 & 50,00 & 50,00 \\
\hline
\end{tabular}

${ }^{1}$ Níveis de garantia (por kg em elementos ativos): cálcio 120,00g; fósforo 87,00g; sódio 147,00g; enxofre 18,00g; cobre $590,00 \mathrm{mg}$; cobalto $40,00 \mathrm{mg}$; cromo $20,00 \mathrm{mg}$; ferro $1.800,00 \mathrm{mg}$; iodo $80,00 \mathrm{mg}$; manganês $1.300,00 \mathrm{mg}$; selênio, 15,00mg; zinco 3.800,00mg; molibdênio 300,00mg; flúor máximo 870,00mg; Solubilidade do fósforo (P) em ácido cítrico a $2 \%$ mínimo $-95 \%$.

Foram coletadas amostras dos ingredientes e das dietas para determinação das composições químico-bromatológicas (Tab. 2 e 3). As análises de matéria seca (MS), matéria orgânica (MO), proteína bruta $(\mathrm{PB})$, extrato etéreo $(\mathrm{EE})$, matéria mineral (MM), nitrogênio insolúvel em detergente neutro (NIDN) e detergente ácido (NIDA), celulose e lignina foram realizadas seguindo procedimentos da AOAC (Association..., 1990). Os teores de fibra em detergente neutro (FDN) e em detergente ácido (FDA) foram determinados de acordo com Van Soest et al. (1991); o de hemicelulose por diferença entre FDN e FDA, bem como os de carboidratos não fibrosos (CNF), calculados conforme Sniffen et al. (1992).

O período experimental foi de 68 dias, sendo sete dias de adaptação dos animais às dietas, instalações e manejo, e 61 dias de colheita de dados. As dietas foram oferecidas duas vezes ao dia, às nove e às 16 horas, e a água foi oferecida à vontade. As sobras foram pesadas diariamente, para reajuste da quantidade de alimento fornecido, permitindo sobras entre 10 e $20 \%$. A quantidade de alimento ofertado e as respectivas sobras foram pesadas diariamente e registradas para determinação do consumo diário por animal.

Tabela 2. Composição químico-bromatológica dos ingredientes das dietas experimentais de caprinos

\begin{tabular}{lcccc}
\hline Item & $\begin{array}{c}\text { Farelo de } \\
\text { milho }\end{array}$ & $\begin{array}{c}\text { Farelo de } \\
\text { soja }\end{array}$ & $\begin{array}{c}\text { Torta de } \\
\text { girassol }\end{array}$ & $\begin{array}{c}\text { Feno Tifton-85 } \\
\text { (Cynodon sp) }\end{array}$ \\
\hline Matéria seca (\%) $^{1}$ & 88,57 & 89,17 & 91,85 & 86,81 \\
Matéria orgânica $^{1}$ & 98,86 & 94,41 & 94,90 & 92,65 \\
Cinzas $^{1}$ & 1,14 & 5,59 & 5,10 & 7,35 \\
Proteína bruta $^{1}$ & 7,83 & 48,73 & 33,73 & 6,16 \\
Extrato etéreo $^{1}$ & 4,11 & 1,93 & 6,85 & 1,12 \\
NID $^{2}$ neutro (\%N total) & 10,36 & 3,84 & 9,11 & 39,18 \\
NID $^{2}$ ácido $(\% \mathrm{~N}$ total) & 3,15 & 2,18 & 3,70 & 18,77 \\
Fibra em detergente neutro $^{1}$ & 10,91 & 10,17 & 32,23 & 79,52 \\
Fibra em detergente ácido $^{1}$ & 3,58 & 7,79 & 26,61 & 47,60 \\
Hemicelulose $^{1}$ & 7,33 & 2,38 & 5,62 & 31,91 \\
Celulose $^{1}$ & 2,72 & 7,16 & 19,56 & 38,19 \\
Lignina $^{1}$ & 0,82 & 0,63 & 7,05 & 9,41 \\
Carboidratos não fibrosos $^{1}$ & 76,01 & 33,58 & 22,09 & 5,85 \\
\hline
\end{tabular}

${ }^{1} \%$ da MS; ${ }^{2}$ nitrogênio insolúvel em detergente.

A avaliação do comportamento ingestivo foi realizada por meio da observação visual individual dos animais, registrando-se os tempos gastos com as atividades de ingestão, ruminação e ócio, em intervalos de cinco minutos, durante
24 horas, conforme Johnson e Combs (1991). As observações comportamentais foram efetuadas em três períodos, com intervalos de 15 dias. Durante a observação noturna, o ambiente foi mantido com iluminação artificial. As eficiências 
de ingestão (EI) e de ruminação (ERU) da MS, da FDN e o tempo de mastigação total (TMT $\mathrm{min} / \mathrm{dia}$ ) foram calculados conforme a metodologia descrita por Burger et al. (2000), por meio das seguintes equações:

EIMS = CMS/TI e EIFDN = CFDN/TI, em que: EIMS: eficiência de ingestão de MS (g MS ingerida/h);

EIFDN: eficiência de ingestão FDN (g FDN ingerida/h);

CMS $(\mathrm{g})$ = consumo diário de MS;
CFDN (g)= consumo diário de FDN;

$\mathrm{TI}=$ tempo gasto em ingestão diariamente $(\mathrm{h})$.

ERUMS $=$ CMS/TRU e ERUFDN =

CFDN/TRU, em que:

ERUMS: eficiência de ruminação da MS (g MS ruminada/h);

ERUFDN: eficiência de ruminação da FDN (g FDN ruminada/h);

TRU: tempo gasto em ruminação diariamente (h).

TMT= TI + TRU, em que:

TMT: tempo de mastigação total (min/dia).

Tabela 3. Composição químico-bromatológica de dietas experimentais de caprinos, de acordo com a inclusão de torta de girassol

\begin{tabular}{lcccc}
\hline \multirow{2}{*}{ Item } & \multicolumn{4}{c}{ Torta de girassol $(\%)$} \\
\cline { 2 - 4 } & 0 & 8 & 16 & 24 \\
\hline Matéria seca (\%) $^{*}$ Matéria orgânica $^{1}$ & 87,97 & 88,20 & 88,43 & 88,65 \\
Cinzas $^{1}$ & 93,41 & 93,32 & 93,53 & 93,18 \\
Proteína bruta $^{1}$ & 6,59 & 6,68 & 6,75 & 6,82 \\
Extrato etéreo $^{1}$ & 13,16 & 13,10 & 13,04 & 12,99 \\
Fibra em detergente neutro $^{1}$ & 2,21 & 2,54 & 2,87 & 3,19 \\
Fibra em detergente ácido $^{1}$ & 44,92 & 46,65 & 48,37 & 50,08 \\
Hemicelulose $^{1}$ & 26,18 & 27,79 & 29,39 & 30,98 \\
Lignina $^{1}$ & 18,73 & 18,86 & 18,98 & 19,09 \\
NID $^{2}$ neutro (\% N total) & 5,07 & 5,58 & 6,08 & 6,57 \\
NID $^{2}$ ácido (\% N total) & 23,61 & 23,83 & 24,06 & 24,30 \\
Carboidratos não fibrosos $^{1}$ & 10,75 & 10,85 & 10,94 & 11,03 \\
EM (Mcal/kg) $^{3}$ & 33,11 & 31,04 & 28,96 & 26,92 \\
\end{tabular}

${ }^{1} \%$ da MS; ${ }^{2}$ nitrogênio insolúvel em detergente; ${ }^{3}$ calculado por estimativa, segundo NRC (Nutrient..., 2001).

Durante o período experimental, foram obtidos os dados (Tab. 4) referentes à temperatura ambiente (TA), umidade relativa do ar (UR) e temperatura do globo negro (TGN), por meio das leituras do termo-higrômetro digital e do globo termômetro, ambos instalados no interior do aprisco a aproximadamente dois metros do piso. A partir dos valores registrados, determinou-se o índice de temperatura do globo negro e umidade $(\mathrm{ITGU}=\mathrm{TGN}+0,36 *(\mathrm{TPO})+41,5)$, segundo
Buffington et al. (1981), em que TPO refere-se à temperatura do ponto de orvalho. $O$ índice de temperatura e umidade (ITU $=\mathrm{TA}+0,36 *(\mathrm{TPO})$ $+41,2)$ foi calculado conforme Baeta e Souza (1997), e para o cálculo da temperatura do ponto de orvalho, utilizou-se a equação TPO = $\left.{ }^{8} \sqrt{\mathrm{UR}} / 100 *[112+(0,9 * \mathrm{TA})]+(0,1 * \mathrm{TA})-112\right)$. As leituras das variáveis ambientais foram realizadas duas vezes por semana, às oito e às 15 horas.

Tabela 4. Valores médios de temperatura ambiente, umidade relativa do ar, temperatura do globo negro, temperatura do ponto de orvalho, índice de temperatura do globo e umidade, e índice de temperatura e umidade, nos períodos da manhã e tarde, durante experimento realizado com caprinos

\begin{tabular}{lcc}
\hline Variável & Manhã & Tarde \\
\hline Temperatura ambiente $\left({ }^{\circ} \mathrm{C}\right)$ & 28,00 & 30,14 \\
Umidade relativa do ar $(\%)$ & 75,42 & 62,14 \\
Temperatura do globo negro $\left({ }^{\circ} \mathrm{C}\right)$ & 27,15 & 30,28 \\
Temperatura do ponto de orvalho $\left({ }^{\circ} \mathrm{C}\right)$ & 23,34 & 21,98 \\
Índice de temperatura do globo e umidade & 77,75 & 79,51 \\
Índice de temperatura e umidade & 77,68 & 79,25 \\
\hline
\end{tabular}


Imediatamente após a leitura das variáveis ambientais realizava-se a avaliação das seguintes características fisiológicas: temperatura retal (TR), frequência respiratória (FR), frequência cardíaca (FC) e temperatura superficial da pele (TS). A TR foi medida com o uso de termômetro clínico digital inserido no reto do animal, por um período de dois minutos. A FR foi obtida pela contagem dos movimentos do flanco, usando-se cronômetro por um período de 30 segundos, sendo o resultado multiplicado por dois, para determinação em minutos (mov/min). A FC foi aferida pela contagem dos batimentos cardíacos em um período de 20 segundos, utilizando-se estetoscópio e cronômetro, sendo o resultado multiplicado por três, para determinação em minutos (bat $/ \mathrm{min}$ ). A TS foi medida em quatro pontos distintos do corpo do animal: paleta e perna, direita e esquerda, com o auxílio de um termômetro infravermelho digital, com mira laser, tendo como resultado o valor médio de todas as medidas.

O delineamento experimental utilizado foi o inteiramente ao acaso, com quatro tratamentos e oito repetições. Os dados obtidos foram submetidos a análises de variância e regressão, por meio do pacote estatístico SAS/2004, versão 9.1, a 5\% de significância.

\section{RESULTADOS E DISCUSSÃO}

Os tempos despendidos em ruminação, ócio e o TMT não foram influenciados $(\mathrm{P}>0,05)$ pela inclusão crescente de torta de girassol nas dietas (Tab. 5).

Tabela 5. Consumos de matéria seca (CMS) e fibra em detergente neutro (CFDN), tempos despendidos em ruminação (TRU) e ócio, e tempo de mastigação total (TMT) obtidos de cabritos $1 / 2$ sangue Boer alimentados com dietas contendo torta de girassol oriunda da produção de biodiesel

\begin{tabular}{|c|c|c|c|c|c|c|c|}
\hline \multirow{2}{*}{ Variável } & \multicolumn{4}{|c|}{ Torta de girassol (MS\%) } & \multirow{2}{*}{$\begin{array}{l}\mathrm{CV} \\
(\%)\end{array}$} & \multicolumn{2}{|c|}{ Efeito } \\
\hline & 0 & 8 & 16 & 24 & & Lin & Quad \\
\hline CMS (g/dia) & 699 & 674 & 643 & 690 & 18,37 & ns & $\mathrm{ns}$ \\
\hline CFDN (g/dia) & 247 & 253 & 237 & 286 & 18,58 & ns & ns \\
\hline TRU (min/dia) & 436,80 & 427,70 & 428,50 & 453,30 & 16,73 & ns & $\mathrm{ns}$ \\
\hline Ócio (min/dia) & 781,40 & 790,60 & 787,20 & 720,80 & 11,05 & ns & $\mathrm{ns}$ \\
\hline TMT (min/dia) & 658,50 & 649,30 & 652,70 & 719,10 & 12,70 & ns & ns \\
\hline
\end{tabular}

$\overline{\mathrm{CV}}=$ coeficiente de variação; Lin = efeito linear; Quad = efeito quadrático; ns = não significativo.

De acordo com Van Soest (1994), o teor de FDN nas dietas influencia o tempo gasto com ingestão e o TRU, devido à resistência dessa fração fibrosa à redução do tamanho de partículas. Neste sentido, com o aumento do conteúdo de fibra das dietas, há maior necessidade de processar a digesta ruminal (Dado e Allen, 1995), e, em razão disto, a ruminação pelos animais é aumentada (Mertens, 1997), alterando, assim, o TRU e o tempo despendido em alimentação.

Carvalho et al. (2006), ao avaliarem o comportamento ingestivo de cabras lactantes alimentadas com dietas com diferentes níveis de FDN, verificaram que o aumento da quantidade de fibra na dieta elevou o tempo gasto em alimentação e o TRU, promovendo, consequentemente, aumento do TMT. Entretanto, no presente estudo, embora a inclusão da torta de girassol tenha aumentado os teores de FDN das dietas (Tab. 3), a semelhança do TRU pode ser justificada pelas similaridades do CMS e CFDN, provavelmente ocorridas em razão de os ingredientes das dietas terem sido finamente moídos (Carvalho et al., 2004), anulando, assim, o efeito do tamanho de partículas.

A discretização das séries temporais, como os períodos em refeição, ruminação e ócio (n\%/dia), assim como dos tempos despendidos por período, em ruminação e ócio (min/período), também não diferiram em razão da inclusão da torta de girassol na dieta (Tab. 6). 
Tabela 6. Períodos de refeição, ruminação e ócio, e tempos despendidos por período em ruminação (TRU) e ócio, por cabritos $1 / 2$ sangue Boer alimentados com dietas contendo torta de girassol oriunda da produção de biodiesel

\begin{tabular}{|c|c|c|c|c|c|c|c|}
\hline \multirow{2}{*}{ Variável } & \multicolumn{4}{|c|}{ Torta de girassol (MS\%) } & \multirow{2}{*}{$\begin{array}{l}\mathrm{CV} \\
(\%)\end{array}$} & \multicolumn{2}{|c|}{ Efeito } \\
\hline & 0 & 8 & 16 & 24 & & Lin & Quad \\
\hline Período refeição (n\%/dia) & 15,12 & 16,12 & 13,37 & 15,50 & 18,26 & ns & ns \\
\hline Período ruminação ( $\mathrm{n}$ /dia) & 30,08 & 31,16 & 29,83 & 32,45 & 15,15 & ns & ns \\
\hline Período ócio (n\%/dia) & 40,37 & 43,37 & 40,04 & 42,25 & 9,71 & ns & ns \\
\hline TRU (min/período) & 14,57 & 13,89 & 14,53 & 14,21 & 17,57 & ns & ns \\
\hline Ócio (min/período) & 19,43 & 18,27 & 20,67 & 17,07 & 17,46 & ns & ns \\
\hline
\end{tabular}

$\mathrm{CV}=$ coeficiente de variação; Lin = efeito linear; Quad = efeito quadrático; NS = não significativo.

As eficiências de ingestão e ruminação da MS e da FDN também não foram afetadas $(\mathrm{P}>0,05)$ pela inclusão da torta de girassol na dieta (Tab. 7), provavelmente devido às semelhanças no CMS e CFDN (Tab. 5), uma vez que tais eficiências variam principalmente devido ao consumo de MS e FDN (Arnaud et al., 2005; Freitas et al., 2010). Ao contrário, se o CFDN tivesse aumentado com a inclusão da torta de girassol, provavelmente as eficiências teriam diminuído gradativamente.

Tabela 7. Eficiências de ingestão da matéria seca $\left(\mathrm{EI}_{\mathrm{MS}}\right)$ e da fibra em detergente neutro $\left(\mathrm{EI}_{\mathrm{FDN}}\right)$ e eficiências de ruminação da matéria seca $\left(E R U_{M S}\right)$ e da fibra em detergente neutro $\left(E R U_{F D N}\right)$ por cabritos $1 / 2$ sangue Boer alimentados com dietas contendo torta de girassol oriunda da produção de biodiesel

\begin{tabular}{|c|c|c|c|c|c|c|c|}
\hline \multirow{2}{*}{ Variável } & \multicolumn{4}{|c|}{ Torta de girassol (MS\%) } & \multirow{2}{*}{$\begin{array}{l}\mathrm{CV} \\
(\%)\end{array}$} & \multicolumn{2}{|c|}{ Efeito } \\
\hline & 0 & 8 & 16 & 24 & & Lin & Quad \\
\hline $\mathrm{EI}_{\mathrm{MS}}(\mathrm{g} \mathrm{MS} / \mathrm{h})$ & 194,20 & 177,00 & 165,80 & 157,40 & 24,36 & ns & ns \\
\hline $\mathrm{EI}_{\mathrm{FDN}}(\mathrm{g} F D N / \mathrm{h})$ & 69,19 & 65,72 & 60,70 & 65,14 & 23,63 & ns & ns \\
\hline $\mathrm{ERU}_{\mathrm{MS}}(\mathrm{g} \mathrm{MS} / \mathrm{h})$ & 97,33 & 91,64 & 92,83 & 90,26 & 23,44 & ns & ns \\
\hline $\mathrm{ERU}_{\mathrm{FDN}}(\mathrm{g}$ FDN/h$)$ & 34,89 & 34,22 & 33,76 & 37,37 & 22,01 & ns & ns \\
\hline
\end{tabular}

$\mathrm{CV}=$ coeficiente de variação; Lin = efeito linear; Quad = efeito quadrático; ns = não significativo.

Sabe-se que as $\mathrm{EI}_{\mathrm{MS}}$ e $\mathrm{ERU}_{\mathrm{MS}}$ podem ser reduzidas quando são fornecidas aos animais dietas com elevado tamanho de partícula ou alto teor de fibra, tendo em vista a maior dificuldade para reduzir o tamanho das partículas originadas destes materiais fibrosos, com consequente queda na ingestão de alimentos (Dulphy et al., 1980; Van Soest, 1994). Da mesma forma, Carvalho et al. (2006) observaram que, em cabras lactantes alimentadas com dietas contendo diferentes níveis de FDN, também houve redução nas eficiências de alimentação e ruminação com o aumento do teor de FDN das dietas.

Entretanto, embora os teores de FDN das dietas tenham aumentado com a inclusão da torta de girassol (Tab. 3), as semelhanças das $\mathrm{ERU}_{\mathrm{MS}} \mathrm{e}$ das $E_{\mathrm{FDN}}$ ocorreram provavelmente em virtude da similaridade da característica física da fibra das dietas, tendo em vista que os ingredientes foram finamente moídos, reduzindo, com isso, o estímulo à ruminação pelo menor tamanho de partículas.

Das variáveis comportamentais avaliadas, apenas os tempos gastos em ingestão (min/dia e $\mathrm{min} /$ período $)$ foram influenciados $(\mathrm{P}<0,05)$ pelas dietas (Fig. 1a e 1b). Pode-se notar que os cabritos consumiram mais vagarosamente, à medida que se elevavam os níveis de torta de girassol nas dietas, provavelmente em decorrência de uma menor palatabilidade desta torta, que acabou culminando na queda gradativa da aceitabilidade das dietas compostas pelos maiores níveis deste coproduto, provocando maior seleção dos alimentos pelos animais, conforme Carvalho et al. (2004). 

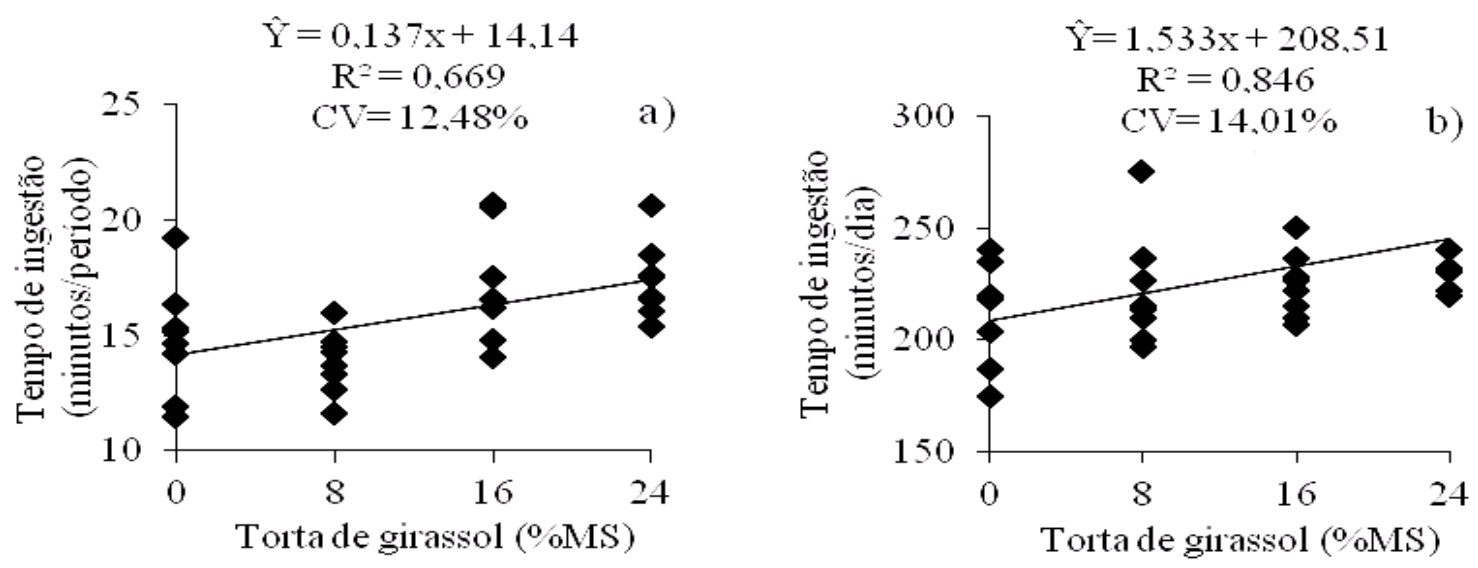

Figura 1. Tempos de ingestão: a) min/período; b) min/dia; por cabritos 1/2 sangue Boer alimentados com dietas contendo torta de girassol oriunda da produção de biodiesel

Com relação às características fisiológicas, sabese que a ingestão de alimentos influencia a produção de calor endógeno nos ruminantes, a qual varia tanto em função da quantidade quanto da qualidade do alimento ingerido (Baccari Júnior, 2001). De acordo com Barcelos et al. (1989), as dietas mais fibrosas proporcionam aos animais maiores FR e TR, uma vez que a maior ingestão dos componentes fibrosos aumenta a produção de acetato no rúmen, elevando a produção de calor endógeno.

No entanto, pode-se observar que a inclusão da torta de girassol nas dietas não alterou $(\mathrm{P}>0,05)$ as características fisiológicas dos cabritos (Tab. 8), provavelmente pelo fato de o CFDN ter sido similar (Tab. 5), e, em razão disto, ter havido semelhança na produção de calor endógeno proveniente da fermentação desta fração fibrosa. Ademais, vale ressaltar que, com a diminuição dos teores de CNF das dietas (Tab. 3), esperavase ainda uma provável queda no consumo de CNF, e com isso a quantidade desta fração fibrosa a ser fermentada talvez fosse menor, com consequente redução da produção de calor endógeno (Gomes et al., 2008), beneficiando a manutenção das características fisiológicas dentro dos limites normais para caprinos.

Tabela 8. Frequências respiratória (FR) e cardíaca (FC) e temperaturas retal (TR) e superficial (TS) de cabritos $1 / 2$ sangue Boer alimentados com dietas contendo torta de girassol oriunda da produção de biodiesel

\begin{tabular}{|c|c|c|c|c|c|c|c|}
\hline \multirow{2}{*}{ Variável } & \multicolumn{4}{|c|}{ Torta de girassol (\%MS) } & \multirow{2}{*}{$\begin{array}{l}\text { CV } \\
(\%)\end{array}$} & \multicolumn{2}{|c|}{ Efeito } \\
\hline & 0 & 8 & 16 & 24 & & Lin & Quad \\
\hline \multicolumn{8}{|c|}{ FR (mov/min) } \\
\hline Manhã & 35,64 & 34,35 & 31,39 & 32,10 & 10,20 & ns & ns \\
\hline Tarde & 47,71 & 47,17 & 46,25 & 48,57 & 8,58 & ns & ns \\
\hline \multicolumn{8}{|c|}{$\mathrm{FC}$ (bat/min) } \\
\hline Manhã & 87,69 & 89,14 & 89,10 & 89,17 & 8,51 & ns & ns \\
\hline Tarde & 97,03 & 94,82 & 95,30 & 95,51 & 7,46 & ns & ns \\
\hline \multicolumn{8}{|l|}{$\mathrm{TR}\left({ }^{\circ} \mathrm{C}\right)$} \\
\hline Manhã & 38,25 & 38,38 & 38,05 & 38,16 & 0,57 & ns & ns \\
\hline Tarde & 38,73 & 38,78 & 38,72 & 38,19 & 0,45 & ns & ns \\
\hline \multicolumn{8}{|l|}{$\mathrm{TS}\left({ }^{\circ} \mathrm{C}\right)$} \\
\hline Manhã & 31,57 & 31,60 & 31,78 & 31,55 & 1,91 & ns & ns \\
\hline Tarde & 30,83 & 30,79 & 31,15 & 31,02 & 1,94 & ns & ns \\
\hline
\end{tabular}

$\overline{\mathrm{CV}}$ = coeficiente de variação; Lin = efeito linear; Quad = efeito quadrático; ns = não significativo. 
Apesar de as dietas não terem alterado as características fisiológicas dos cabritos, e sabendo-se que na região Nordeste os animais estão sob condições de temperatura e umidade inadequadas em determinadas épocas do ano (Rocha et al., 2009), pode-se verificar, pelos dados obtidos nas leituras das variáveis ambientais (Tab. 4), que, independentemente do período (manhã e tarde), os valores de TA encontrados superaram a temperatura crítica entre 24 e $27^{\circ} \mathrm{C}$, para a maioria das espécies dos animais de produção (Fuquay, 1981), da mesma forma que a UR do ar se manteve acima da ideal (60 a 70\%) para os animais domésticos (Müller, 1989), lembrando que a UR, quando associada com alta TA, pode causar desconforto térmico aos animais, por prejudicar os processos de dissipação de calor corporal (Armstrong, 1994).

Em consequência dos elevados valores de TA e UR, também houve aumentos no ITGU e ITU (Tab. 4), que estão relacionados ao conforto térmico dos animais. De acordo com o National Weather Service dos EUA, citado por Baêta (1985), os valores de ITGU até 74, de 74 a 78, de 79 a 84 e acima de 84 definem situação de conforto, de alerta, de perigo e de emergência, respectivamente, para ruminantes. Com relação ao ITU, segundo Barbosa e Silva (1995), os valores inferior ou igual a 70, de 71 a 78 , de 79 a 83 e acima de 83 indicam condições normal, crítica, de perigo e de emergência, respectivamente (Barbosa e Silva, 1995). Sendo assim, pelos resultados de ITGU e ITU obtidos neste estudo, pode-se inferir que, no período da manhã, os animais estiveram em situação crítica ou de alerta, e no período da tarde, o ambiente foi mais prejudicial, ficando os animais em condição de perigo, caracterizando o desconforto térmico ou estresse calórico deles.

Em razão disto, as FR e FC dos cabritos nos períodos da manhã e tarde (Tab. 8) ficaram acima dos limites descritos para caprinos, que variam de 12 a $25 \mathrm{mov} / \mathrm{min}$ e de 70 a $80 \mathrm{bat} / \mathrm{min}$, respectivamente (Kolb, 1987). Entretanto, pelas médias de FR obtidas neste estudo (Tab. 6), pode-se dizer que, no período da manhã, os cabritos não estavam em estresse calórico e que, no período da tarde, apresentaram estresse baixo, haja vista que a severidade do estresse pelo calor pode ser quantificada pela avaliação da FR (Silanikove, 2000) e que os valores entre 40-60, 60-80 e 80-120mov/min indicam, respectivamente, estresse baixo, de médio a alto e alto, respectivamente.

É importante salientar que os ruminantes inicialmente dissipam calor para o ambiente por meio de mecanismos sensíveis de perda de calor (radiação, condução e convecção), sendo esta perda dependente do gradiente de temperatura entre a pele dos animais e o ar. No entanto, quando a TA está próxima à da superfície cutânea, os mecanismos sensíveis têm sua eficiência reduzida, e os latentes (evaporação respiratória e evaporação cutânea) tornam-se os principais processos de perda de calor (Silva, 2000). Sendo assim, tendo em vista os valores próximos entre a TA (Tab. 4) e a TS dos cabritos (Tab. 8), pode-se inferir que, nestas condições climáticas, os mecanismos sensíveis provavelmente são insuficientes para manter a homeotermia nestes animais.

Considerando-se as médias de FR (Tab. 8) e sabendo-se que a TR reflete o acúmulo de calor no organismo animal, devido ao excesso de calor recebido do ambiente ao longo do dia, somado à produção de calor interna e à incapacidade dos mecanismos termorreguladores em eliminar o calor excedente (Nääs, 1998), pela média de TR no período da tarde $\left(38,6^{\circ} \mathrm{C}\right)$, nota-se que esta estava dentro da faixa normal $\left(38,5\right.$ a $\left.40,5^{\circ} \mathrm{C}\right)$ para caprinos (Kolb, 1987), evidenciando que a FR foi suficientemente capaz de impedir que o estresse calórico dos cabritos fosse ainda maior no período da tarde.

\section{CONCLUSÕES}

A torta de girassol pode ser incluída até $24 \%$ da MS em dietas de cabritos $1 / 2$ sangue Boer, sem comprometer o comportamento ingestivo e as respostas fisiológicas desses animais. Sob as condições climáticas avaliadas, o fornecimento de dietas com até $24 \%$ de MS de torta de girassol não ameniza ou potencializa o estresse calórico. 


\section{REFERÊNCIAS}

AGY, M.S.F.A.; OLIVEIRA, R.L.; RIBEIRO, C.V.D.M. et al. Sunflower cake from biodiesel production fed to crossbred Boer kids. Rev. Bras. Zootec., v.41, p.123-130, 2012.

ARMSTRONG, D.V. Heat stress interaction with shade and cooling. J. Dairy Sci., v.77, p.2044-2050, 1994.

ARNAUD, B.L.; VÉRAS, A.S.C.; FERREIRA, M.A. et al. Efeitos da substituição do feno de capim-tifton e do farelo de milho pela palma forrageira e pelo farelo de soja sobre a ingestão de alimentos e parâmetros fisiológicos. Acta Sci. Anim., v.27, p.475-482, 2005.

ASSOCIATION of official analytical chemistryAOAC. 12nd ed. Washington, DC: AOAC, 1990. 1094p.

BACCARI Jr., F. Manejo ambiental da vaca leiteira em climas quentes. Londrina: Editora da Universidade Estadual de Londrina, 2001. 142p.

BAÊTA, F.C. Responses of lactating dairy cows to the combined effects of temperature, humidity and wind velocity in the warm season. 1985. 218f. Tese (Doutorado em Agricultural Engineering-Structures and Environment) - State University of Missouri, Columbia, EUA

BAETA, F.C.; SOUZA, C.F. Ambiência em edificações rurais: conforto animal. Viçosa: Universidade Federal de Viçosa, 1997. 246p.

BARBOSA, O.R.; SILVA, R.G. Índice de conforto térmico para ovinos. Rev. Bras. Zootec., v.24, p.874883, 1995.

BARCELOS, A.F.; GARCIA, J.A.; CARDOSO, R.M. et al. Reações fisiológicas de bubalinos, zebuínos, taurinos e seus mestiços sob efeito de clima e dieta. I. Temperatura retal e frequência respiratória. Rev. Bras. Zootec., v.18, p.32-41, 1989.

BORJA, M.S.; OLIVEIRA, R.L.; RIBEIRO, C.V.D.M. et al. Effects of feeding licury (Syagrus coronate) cake to growing goats. Asian-Aust. J. Anim. Sci., v.23, p.1436-1444, 2010.

BUFFINGTON, D.E.; COLLAZZO-AROCHO, A.; CANTON, G.H. Black globe humidity index (BGHI) as comfort equation for dairy cows. Trans. ASAE, v.24, p.711-714, 1981

BURGER, P.J.; PEREIRA, J.C.; SILVA, J.F.C. et al. Comportamento ingestivo em bezerros holandeses alimentados com dietas contendo diferentes níveis de concentrado. Rev. Bras. Zootec., v.29, p.236-242, 2000 .
CAMPBELL, C.P.; MARSHALL, S.A.; MANDELL, I.B. Effects of source of dietary neutral detergent fiber on chewing behavior in beef cattle fed pelleted concentrates with or without supplemental roughage. J. Anim. Sci., v.70, p.894-903, 1992.

CARVALHO, G.G.P.; PIRES, A.J.V.; SILVA, F.F. et al. Comportamento ingestivo de cabras leiteiras alimentadas com farelo de cacau ou torta de dendê. Pesq. Agropec. Bras., v.39, p.919-925, 2004.

CARVALHO, S.; RODRIGUES, M.T.; BRANCO, R.H. et al. Comportamento ingestivo de cabras Alpinas em lactação alimentadas com dietas contendo diferentes níveis de fibra em detergente neutro proveniente da forragem. Rev. Bras. Zootec., v.35, p.562-568, 2006.

CORREIA, B.R.; OLIVEIRA, R.L.; JAEGER, S.M.P.L. et al. Consumo, digestibilidade e $\mathrm{pH}$ ruminal de novilhos submetidos a dietas com tortas oriundas da produção do biodiesel em substituição ao farelo de soja. Arq. Bras. Med. Vet. Zootec., v.63, p.356-363, 2011.

DADO, R.G.; ALLEN, M.S. Intake limitation, feeding behavior and rumen function of cows challenged with rumen fill from dietary fiber or inert bulk. J. Dairy Sci., v.78, p.118-133, 1995.

DULPHY, J.P.; REMOND, B.; THERIEZ, M. Ingestive behavior and related activities in ruminants. In: RUCKEBUSH, Y.; THIVEND, P. Digestive physiology and metabolism in ruminants. Lancaster: MTP, 1980. p.103-122.

FREITAS, L.S.; SILVA, J.H.S.; SEGABINAZZI, L.R. et al. Substituição da silagem de milho por silagem de girassol na dieta de novilhos em confinamento: comportamento ingestivo. Rev. Bras. Zootec., v.39, p.225-232, 2010.

FUQUAY, J.W. Heat stress as it affects animal production. J. Anim. Sci., v.52, p.164-174, 1981.

GOMES, C.A.V.; FURTADO, D.A.; MEDEIROS, A.N. et al. Efeito do ambiente térmico e níveis de suplementação nos parâmetros fisiológicos de caprinos Moxotó. Rev. Bras. Eng. Agric. Ambiental, v.12, p.213-219, 2008.

HOLANDA JUNIOR, E.V. Sistemas de produção de pequenos ruminantes no semi-árido do Nordeste Brasileiro. Sobral: Embrapa caprinos, 2006. 35 p.

INSTITUTO nacional de meteorologia. Normais Climatológicas 1961 a 1990. Brasília: INMET, 1992. 84p.

JOHNSON, T.R.; COMBS, D.K. Effects of prepartum diet, inert rumen bulk, anddietary polyethylene glycol on dry matter intake of lactating dairy cows. J. Dairy Sci., v.74, p.933-944, 1991. 
KOLB, E. Fisiologia veterinária. 4.ed. Rio de Janeiro: Guanabara Koogan, 1987. 612p.

MACOME, F.M.; OLIVEIRA, R.L.; BAGALDO, A.R. et al. Productive performance and carcass characteristics of lambs fed diets containing different levels of palm kernel cake. Rev. MVZ Cordoba, v.16, p.2659-2667, 2011.

MENDONÇA, S.S.; CAMPOS, J.M.S.; VALADARES FILHO, S.C. et al. Comportamento ingestivo de vacas leiteiras alimentadas com dietas à base de cana-de-açúcar ou silagem de milho. Rev. Bras. Zootec., v.33, p.723-728, 2004.

MENEGHETTI, C.C.; DOMINGUES, J.L. Características nutricionais e uso de subprodutos da agroindústria na alimentação de bovinos. Rev. Eletr. Nutrit., v.5, p.512-536, 2008.

MERTENS, D.R. Creating a system for meeting the fiber requirements of dairy cows. J. Dairy Sci., v.80, p.1463-1481, 1997.

MÜLLER, R.P. Bioclimatologia aplicada aos animais domésticos. Porto Alegre: Sulina, 1989. 262p.

NÄÄS, I.A. Tipologia de instalações em clima quente. In: SIMPÓSIO BRASILEIRO DE AMBIÊNCIA NA PRODUÇÃO DE LEITE, 1., 1998, Piracicaba. Anais... Piracicaba: ESALQ, $1998 . \quad$ p.146-155. (Palestra)

NEIVA, J.N.M.; TEIXEIRA, M.; TURCO, S.H.N. et al. Efeito do estresse climático sobre os parâmetros produtivos e fisiológicos de ovinos Santa Inês mantidos em confinamento na região litorânea do Nordeste do Brasil. Rev. Bras. Zootec., v.33, p.668678, 2004.

NUTRIENT requirements of dairy cattle. 7.ed. Washington: National Academy of Sciences, 2001. 362 p.

NUTRIENT requirements of small ruminant. Washington: National Academies, 2007. 281p.

OLIVEIRA, R.L.; LEÃO, A.G.; RIBEIRO, O.L. et al. Co-produtos do biosiesel na alimentação de ruminantes. In: SIMPÓSIO NORDESTINO DE ALIMENTAÇÃO DE RUMINANTES, 12., 2010, Mossoró. Anais... Mossoró: SNPA, 2010. CD-ROM (Palestra).
PALMIERI, A.D.; OLIVEIRA, R.L.; RIBEIRO, C.V.D.M. et al. Effects of substituting soybean meal for sunflower cake in the diet on the growth and carcass traits of crossbred Boer goat kid. Asian-Aust. J. Anim. Sci., v.25, p.59-65, 2012.

ROCHA, R.R.C.; COSTA, A.P.R.; AZEVEDO, D.M.M.R. et al. Adaptabilidade climática de caprinos Saanen e Azul no Meio-Norte do Brasil. Arq. Bras. Med. Vet. Zootec., v.61, p.1165-1172, 2009.

STATISTICAL Analysis System - SAS INSTITUTE - INC. SAS/STAT User's guide. Version 9.1, Cary, NC: SAS Institute Inc., 2004.

SILANIKOVE, N. Effects of heat stress on the welfare of extensively managed domestic ruminants. Livest. Prod. Sci., v.67, p.1-18, 2000.

SILVA, R.G. Introdução à bioclimatologia. São Paulo: Nobel, 2000. 286p.

SNIFFEN, C.J.; CONNOR, J.D.; VAN SOEST, P.J. A net carbohydrate and protein system for evaluation cattle diets. II. Carbohydrate and protein availability. J. Anim. Sci., v.70, p.3562-3577, 1992.

SOUSA, W.H. Agronegócio da caprinocultura de corte no Brasil. Rev. Tecnol. Cienc. Agropec, v.1, p.51-58, 2007.

SOUZA, B.B.; ANDRADE, I.S.; PEREIRA FILHO, J.M. et al. Efeito do ambiente e da suplementação no comportamento alimentar e no desempenho de cordeiros no semiárido. Rev. Caatinga, v.24, p.123129, 2011.

SOUZA, B.B.; SILVA, R.M.N.; MARINHO, M.L. et al. Parâmetros fisiológicos e índice de tolerância ao calor de bovinos da raça Sindi no semi-árido paraibano. Cienc. Agrotec., v.31, p.883-888, 2007.

SOUZA, W.; BARBOSA, O.R.; MARQUES, J.A. et $a l$. Behavior of beef cattle in silvipastoral systems with eucalyptus. Rev. Bras. Zootec., v.39, p.677-684, 2010.

VAN SOEST, P.J. Nutritional ecology of the ruminant. 2nd ed. New York: Cornell University, 1994. $476 \mathrm{p}$.

VAN SOEST, P.J.; ROBERTSON, J.B.; LEWIS, B.A. Methods for dietary fiber, neutral detergent fiber, and nonstarch polyssacharides in relation to animal nutrition. J. Dairy Sci., v.74, p.3583-3597, 1991. 